\title{
UM OLHAR PLURICÊNTRICO NO ENSINO DE PORTUGUÊS LÍNGUA NÃO MATERNA: O PAPEL DAS LITERATURAS AFRICANA, MACAENSE E TIMORENSE
}

\author{
UNA MIRADA PLURICÉNTRICA EN LA ENSEÑANZA DE PORTUGUÉS LENGUA \\ NO MATERNA: EL PAPEL DE LAS LITERATURAS AFRICANA, MACAENSE Y \\ TIMORENSE
}

\section{A PLURICENTRIC VIEW OF PORTUGUESE AS A NON-NATIVE LANGUAGE TEACHING: THE ROLE OF AFRICAN, MACANESE AND TIMORESE LITERATURES}

RESUMO: A língua portuguesa é uma língua pluricêntrica e internacional, sendo uma das maiores do mundo, com falantes nativos e aprendizes em diversos países. Contudo, o ensino de Português Língua Não Materna (PLNM) na atualidade, bem como os respectivos materiais didáticos focam apenas em uma ou outra norma do português, o Português Europeu ou o Português Brasileiro. Assim, diante da escassez de materiais didáticos que abordem a língua portuguesa como pluricêntrica, propomos aqui uma discussão e um roteiro, sendo que em nossa proposta utilizamos textos literários como exemplos autênticos das diferentes normas linguísticas existentes do português junto ao trabalho intercultural e ao ensino comunicativo do português. Desta maneira, após a introdução, apresentamos uma discussão teórica sobre o assunto seguida por um exemplo e um roteiro para elaboração. Finalmente, apontamos alguns aspectos positivos e o impacto nos alunos a respeito do uso desse tipo de material.

PALAVRAS-CHAVE: Português Língua Não Materna (PLNM). Pluricentrismo Linguístico. Literatura e ensino de línguas.

RESUMEN: El portugués es una lengua pluricéntrica e internacional, siendo una de las más grandes del mundo, con hablantes nativos y estudiantes en varios países. Sin embargo, la enseñanza del Portugués como Lengua no Materna (PLNM) en la actualidad, así como los respectivos materiales didácticos, se centran únicamente en uno u otro estándar de portugués, el Portugués Europeo o el Portugués Brasileño. Así, dada la escasez de materiales didácticos que aborden la lengua portuguesa como pluricéntrica, proponemos aquí una discusión y un guión. En nuestra propuesta utilizamos textos literarios como auténticos ejemplos de las diferentes normas lingüisticas existentes en portugués junto con la enseñanza intercultural y comunicativa de portugués. En nuestro texto, tras la introducción, presentamos una discusión teórica sobre el tema seguida de un ejemplo y una guía de elaboración. Finalmente, señalamos algunos aspectos positivos y el impacto en los estudiantes con respecto al uso de este tipo de material.

\footnotetext{
${ }^{1}$ Universidade Federal de Goiás (UFG), Samambaia, Goiânia - GO - Brasil. Membro do Núcleo de Estudos de Ecolinguística e Imaginário (NELIM). Doutorado em Linguística (UnB). ORCID: https://orcid.org/0000-00021941-6925. E-mail: albuquerque07@gmail.com
} 
PALABRAS CLAVE: Portugués Lengua no Materna (PLNM). Pluricentrismo lingüístico. Enseñanza de la literatura y la lengua.

ABSTRACT: Portuguese language is a pluricentric and international language, being one of the largest in the world, with native speakers and learners in several countries. However, the current Portuguese as a Non-Native Language (PNNL) teaching and its teaching materials focus one of the two existing Portuguese standards, European Portuguese or Brazilian Portuguese. Furthermore, given the scarcity of teaching materials that address the Portuguese language as pluricentric, we propose here a discussion and a guide for PNNL teaching using literary texts as authentic examples of different Portuguese linguistic norms along with intercultural and communicative teaching of Portuguese. Thus, after the introduction, we present a theoretical discussion on the subject followed by an example and a guide for elaboration. Finally, we point out some positive aspects and the impact on students regarding the use of this type of material.

KEYWORDS: Portuguese as a Non-Native Language (PNNL). Linguistic Pluricentrism. Literature and language teaching.

\section{Introdução}

Nos primeiros estudos sobre pluricentrismo linguístico, a língua portuguesa foi reconhecida como pluricêntrica, apresentando duas normas nacionais distintas, ou seja, dois centros linguísticos, a saber: o Português Europeu (PE) e o Português Brasileiro (PB).

Mesmo com outras normas nacionais em desenvolvimento, principalmente o Português de Moçambique (PM) e o Português de Angola (PA), é possível afirmar que o cenário da lusofonia pouco mudou nas últimas décadas em relação à predominância dos dois grandes centros (Portugal e Brasil), com Portugal assumindo posição principal nas ações, políticas e projetos para o ensino, promoção e difusão do português pelo mundo, enquanto o Brasil possui apenas algumas ações pontuais em andamento. Os demais países lusófonos apresentam contribuições pequenas, quer por certas limitações socioeconômicas, quer pelo fato de adotarem o PE como norma. Ademais, os projetos que visam a promoção do português como língua internacional, propondo algo como uma norma supranacional, ou panlusófona, para o ensino de Português Língua Não Materna (doravante PLNM) geralmente esbarram em entraves governamentais, burocráticos e/ou ideológicos de algum dos países da CPLP (Comunidade dos Países de Língua Portuguesa). Isto leva alguns linguistas a considerar o português como uma língua bicêntrica (e não pluricêntrica), bem como multinacional (e não uma língua internacional). 
Em relação aos materiais didáticos de ensino de PLNM, a situação é semelhante, privilegiando o PE ou o PB, a depender dos autores e o local/editora onde foram produzidos, sendo que materiais que apresentem alguma proposta próxima ao pluricentrismo são raros, limitando-se a cerca de três ou quatro, conforme analisado por Albuquerque (2021).

Dessa maneira, o presente artigo tem como objetivo apresentar a importância de se trabalhar textos literários na aula de PLNM, especialmente de obras ficcionais fora do eixo bilateral Brasil-Portugal da lusofonia. Assim, após esta introdução, oferecemos um subsídio teórico a respeito dos benefícios para o aprendiz quando o professor de PLNM utiliza obras literárias em sala de aula. Em seguida, listamos os livros empregados por nós e propomos diferentes unidades didáticas para usá-los com os aprendizes. Finalmente, depois da análise, exposição e debate feitos no corpo deste artigo, redigimos as considerações finais.

\section{Textos literários e ensino de PLNM}

O lugar e as funções do texto literário nas diferentes abordagens e métodos de ensino de língua estrangeira (LE) foram variados no decorrer da história. Como utilizamos em nossa prática os métodos comunicativos e o ensino intercultural, que estão de acordo com uma proposta pluricêntrica, destacamos que neles os textos literários são usados como um tipo de documento autêntico, dentre vários outros, com o objetivo de desenvolver as "habilidades comunicativas, no sentido de interacionais e interculturais" (TAKAHASHI, 2008, p. 24).

Ainda em Takahashi (2008), além de propostas de atividades que trabalham a compreensão da leitura de textos literários, a autora realiza uma pesquisa, feita por meio de questionários com alunos de PLNM, revelando que a maioria dos aprendizes tem uma expectativa de estudar literatura nas aulas:

Em primeiro lugar, trata-se de uma expectativa, quase uma necessidade. Os alunos, especialmente os de nível intermediário e avançado, esperam que haja uma referência, ou menção, de textos literários, de autores representativos de determinadas épocas, linguagens ou gêneros textuais. Em segundo lugar, essa expectativa vem acrescida de três representações que se imbricam em um todo no processo de assimilação de uma língua estrangeira: aperfeiçoamento lingüístico, aquisição de conhecimentos literários e acesso à cultura do país (TAKAHASHI, 2008, p. 65-66).

Digno de nota é que somado a seu caráter autêntico, o qual foi produzido com fins outros que não o educacional, o texto literário também apresenta um valor fundamental para o 
ensino de PLNM ao possuir, simultaneamente, elementos linguísticos e socioculturais que podem ser explorados de maneiras variadas no processo de ensino-aprendizagem.

Ademais, Bizarro (2008) destaca que a inserção do texto literário na aula de LE apresenta três objetivos: o comunicativo (o qual corresponde ao que chamamos de linguístico), o cultural (ou sociocultural) e o formativo. $\mathrm{O}$ formativo está relacionado aos valores, ao pensamento crítico e à relação do aprendiz com o mundo, elementos presentes nas obras literárias e que podem despertar a reflexão e o debate na aula de PLNM.

Nessa proposta de Bizarro (2008), influenciada por Fonseca (2000), destacam-se as atividades e as competências específicas que podem ser desenvolvidas no aprendiz utilizando a literatura em sala de aula. Em relação aos objetivos linguísticos, são abordadas questões de gêneros e tipologia textual; os diferentes estilos empregados por autores e falantes; temáticas de análise do discurso, como o sujeito, a ideologia, entre outras; e traços específicos das normas nacionais/locais em formação, bem como do português vernáculo oral, principalmente o vocabulário local, neologismos e construções sintáticas. No objetivo cultural, a literatura traz a oportunidade do leitor, o Eu, ver o mundo a partir da visão do Outro, pois o autor oferece temas históricos, políticos, itens da cultura material local, diferentes formas de se contar histórias etc., criando o espaço para o debate sobre as diferenças culturais e desenvolvendo, assim, a competência intercultural. Enquanto o objetivo formativo está relacionado às discussões que ocorrem em sala de aula, as quais procuram despertar autonomia, pensamento crítico e o respeito à alteridade.

Para finalizar, destacamos dois pontos importantes os quais Takahashi $(2008 ; 2015)$ e outros autores já pesquisaram a respeito, são eles: qual é a visão do aprendiz sobre o ensino de literatura na aula de PLNM e como ela deve ser trabalhada em sala para ir além de tarefas simplistas e/ou estereotipadas. Em relação às tarefas, Takahashi (2015) elabora uma proposta na qual os aprendizes possam compreender e construir diferentes significados para o texto literário, bem como produzir gêneros críticos a respeito de suas experiências como leitor. Esta proposta da autora está de acordo com sua pesquisa anterior, na qual revelou que os aprendizes apresentam três representações (aperfeiçoamento linguístico, aquisição de conhecimentos literários e acesso à cultura) sobre o que esperam aprender com a leitura de textos literários na aula de PLNM:

[...] O aperfeiçoamento lingüístico refere-se mais à decodificação situacional da língua (compreensão) - envolvendo a sintaxe e o uso do léxico - do que uma análise gramatical específica. A aquisição de conhecimentos literários diz respeito à representação do panorama histórico da literatura do país e o acesso à cultura é esperado pelo conhecimento interiorizado de que tais 
textos sempre carregam impressões sociais, artísticas, históricas, ou, ainda, morais (TAKAHASHI, 2008, p. 65-66).

Em relação a estereótipos, baseamo-nos na análise de livros didáticos de PLNM que Diniz, Scaramucci e Stradiotti (2009) realizaram, pois os autores criticaram o fato de a construção da imagem do brasileiro, em grande parte dessas obras, não apresentar espaço para reflexão, discussão e produção de diferentes sentidos por parte do aprendiz, sendo apresentadas apenas imagens reconhecidas com marcas de estereotipia, seguidas por atividades gramaticais ou de compreensão textual. Por isso, consideramos a proposta de Takahashi $(2008 ; 2015)$ válida para o trabalho com o texto literário, já que apresenta um espaço para o desenvolvimento de diversas habilidades no aprendiz e a (re)construção de significados.

\section{As literaturas africanas, macaense e timorense no ensino de PLNM}

Como partilhamos da visão do português como uma língua internacional e pluricêntrica, utilizando em nossa prática os métodos comunicativos e o ensino intercultural, sempre tivemos espaço em nossos planejamentos para o trabalho com a literatura brasileira e dos demais países lusófonos em nossa aula de PLNM.

Nas últimas décadas, professores e investigadores vêm se dedicando ao estudo principalmente da literatura africana em língua portuguesa, porém se sabe que tanto a literatura dos países lusófonos africanos, quanto a de Macau e Timor-Leste são fontes de riqueza e conhecimento em várias áreas do saber.

Em Lima (2016), a autora lista uma série de contribuições que a literatura desses países pode oferecer, sendo elas: traços históricos, políticos e culturais; situação de colonização e pós-colonização; pobreza, guerras e conflitos; a questão do negro, do racismo, de etnias, de clãs, de famílias e afins; os diversos sentimentos coletivos e o imaginário dos povos colonizados, especialmente a temática de ódio, ressentimento, raiva etc.; a presença do mágico, do fantástico, de bruxaria, xamanismo, entre outros; diferentes tipos de humor e ironia; a oralidade e a "contação" de histórias; o entrelaçamento de gêneros discursivos na mesma obra; e particularidades linguísticas, principalmente lexical e sintática, do português falado nesses países.

Desta maneira, tendo em vista a proposta de Takahashi $(2008 ; 2015)$ e de Lima (2016), utilizamos a literatura africana, macaense e timorense em nossos cursos de PLNM nos níveis iniciante e avançado, bem como a leitura de contos, trechos ou capítulos de romances 
que servem para o desenvolvimento das quatro habilidades, pois, a partir da compreensão e interpretação dos textos, efetuamos trabalhos com tarefas comunicativas, diferentes momentos de debate, exposição oral, apresentação de trabalhos, produção textual dos alunos e exibição de filmes.

A escolha das obras utilizadas por nós depende dos cursos específicos, das necessidades dos alunos, das instituições e da carga horária, porém fornecemos uma lista de base na Tabela 1. Os critérios principais são a facilidade de acesso aos textos (em formato de livros físicos ou e-books; comercializados por grandes editoras; encontrados em diversos países, como Brasil e Portugal) e a presença de grande parte das características apontadas por Lima (2016), permitindo que cada texto possibilite uma série de atividades e tarefas comunicativas nas aulas de PLNM.

Tabela 1 - Lista de obras literárias

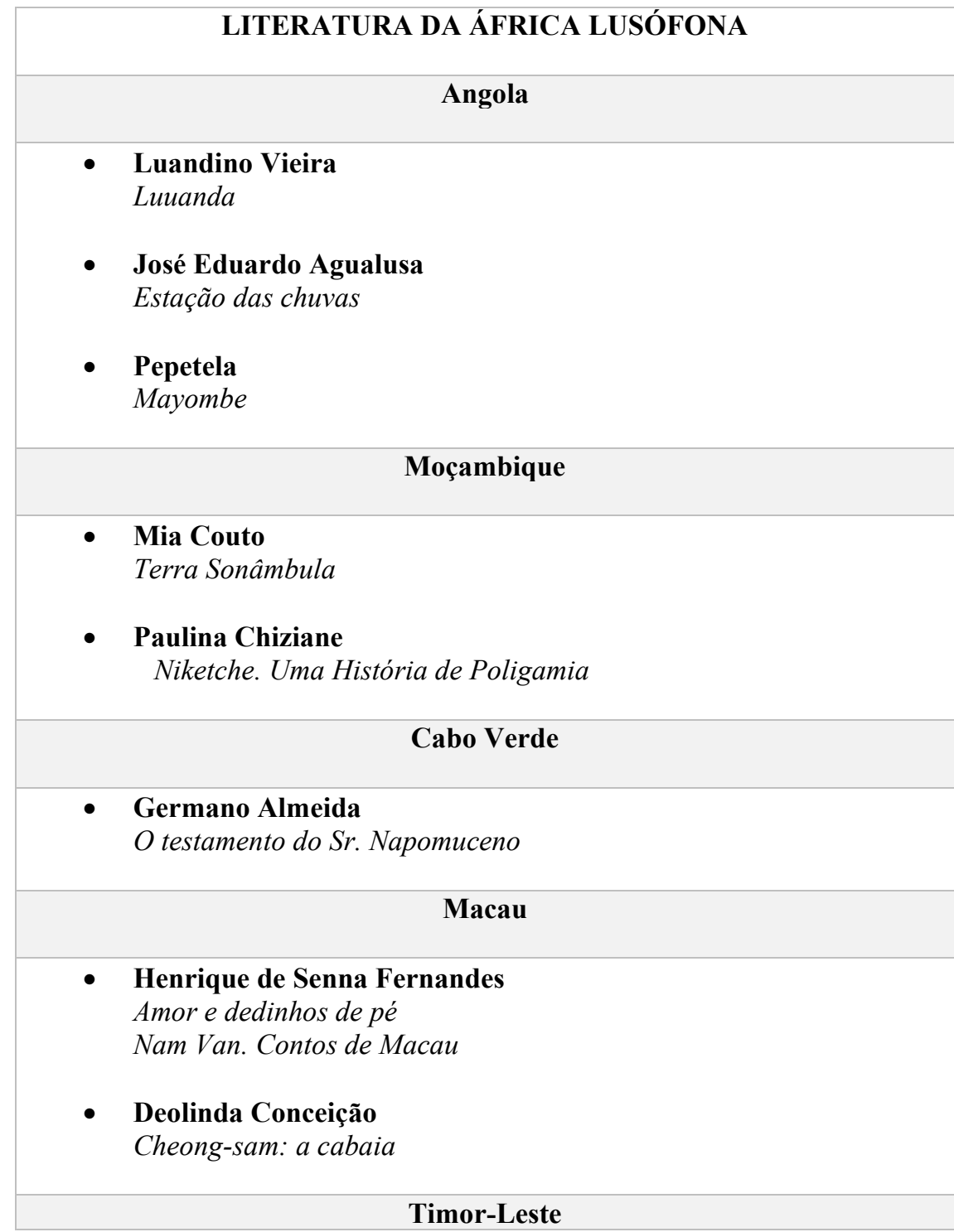




\section{- Luís Cardoso}

Crónicas de uma travessia - a época de Ai-dik-funam

Olhos de coruja, olhos de gato bravo

Fonte: Elaborado pelo autor

Em relação a informações históricas e situação da colonização e do período póscolonização, há obras cujo tempo narrativo se passa no período colonial tardio, como os contos em Luuanda, de Luandino Vieira, e Amor e dedinhos de pé, de Henrique de Senna Fernandes; ou englobam o passar do tempo e a transição de colônia para nação independente, por meio de protagonistas mais velhos com a narrativa acompanhando o período desde a infância até a fase adulta ou a morte do personagem principal, como em $\mathrm{O}$ testamento do $\mathrm{Sr}$. Napomuceno, de Germano Almeida; ou romances no período pós-colonial/pós-independência, como em Niketche. Uma História de Poligamia, de Paulina Chiziane.

Sobre questões políticas, guerras, pobreza, entre outros, há os conflitos e guerras de independência e pós-independência, bem como suas consequências perniciosas à população, os quais são retratados em Estação das chuvas, de José Eduardo Agualusa, Mayombe, de Pepetela, e Crónicas de uma travessia - a época de Ai-dik-funam, de Luís Cardoso.

As questões étnicas, raciais e de preconceitos em geral, tanto na relação do europeu com o africano, como também com os orientais, são abordadas nas obras de Luandino Vieira, Mia Couto, Henrique de Senna Fernandes, Luís Cardoso, entre outros, enquanto que questões de gênero e o papel da mulher nas diferentes sociedades estão presentes em obras como Niketche. Uma História de Poligamia, de Paulina Chiziane, Estação das chuvas, de José Eduardo Agualusa, e Amor e dedinhos de pé, de Henrique de Senna Fernandes.

Em relação ao entrelaçamento de gêneros textuais, as obras listadas aqui são romances ou contos, porém nessas narrativas é possível encontrar aspectos autobiográficos, como em Luuanda, de Luandino Vieira, ou em Mayombe, de Pepetela; características de estudo biográfico e histórico, como em Estação das chuvas, de José Eduardo Agualusa, livro em que é feita uma biografia da poetisa angolana Lídia do Carmo Ferreira e que retrata a história da guerra civil no país; até mesmo características de literatura de viagem, como em Crónicas de uma travessia - a época de Ai-dik-funam, de Luís Cardoso.

Após essas breves palavras sobre as contribuições significativas da literatura africana, macaense e timorense para o ensino de PLNM, listamos os elementos que fazem parte de uma espécie de roteiro que utilizamos para elaborar nossas aulas, sendo nossa proposta didática para o trabalho pluricêntrico com literatura. 
O primeiro passo é a seleção das obras, conforme já citamos as utilizadas por nós, e dos trechos a serem usados no material didático e nas aulas. Digno de nota é que devem ser escolhidas duas ou mais obras de países lusófonos distintos para que se efetue na prática um ensino pluricêntrico. Com a seleção feita, o professor deve pensar também como será efetuada a leitura, somente em sala ou se solicitará a leitura extraclasse das obras.

A segunda etapa consiste em inserir no material didático informações sobre os autores, os países de origem e os contextos históricos nos quais se passam as narrativas dos textos literários. Essas informações também podem ser compartilhadas de outras formas com os aprendizes (datashow, aula expositiva, redes sociais, aplicativos de bate-papo, grupos/ plataformas de turmas ou aulas online etc.).

$\mathrm{Na}$ terceira etapa, com a leitura iniciada, o foco das aulas deve ser na compreensão e interpretação dos textos literários, explorando aspectos da produção oral dos aprendizes (conversa, diálogo, debate, opinião, exposição), solicitando que exponham suas dúvidas, os traços interculturais que consideraram interessantes e suas opiniões sobre o enredo, a atitude dos personagens, entre outras coisas.

A quarta etapa apresenta um trabalho com as competências lexical e gramatical. Em relação ao vocabulário, o professor deve ficar atento aos lexemas que os aprendizes apresentaram dificuldades ou não conheciam, bem como aos itens lexicais culturalmente específicos, como nomes de pratos, flora e fauna locais, entre outros. Enquanto que na competência gramatical recomendamos que o professor aproveite as categorias e construções que surgem com frequência nas obras literárias escolhidas. Como grande parte se trata de narrativas das vidas dos personagens e de acontecimentos históricos nos países lusófonos, o que encontramos de maneira recorrente são as classes de pronome, conjunção e verbo, podendo ser abordadas questões de flexão, concordância, regência e os tipos de oração em português. Assim, o professor escolhe um desses tópicos, mostra como eles aparecem nos textos lidos e faz uso de diversas tarefas para seu ensino em sala de aula.

Vale lembrar que as etapas estão entrelaçadas, sendo uma relacionada e continuando a outra. Desta maneira, a quarta etapa se baseia no conhecimento que o professor teve das dificuldades e das falas dos aprendizes, bem como na escolha das obras para elaborar o material referente ao ensino das competências lexical e gramatical. Da mesma maneira, a quinta e sexta etapas retomam as atividades das etapas anteriores, a saber: com a quinta etapa, o professor retorna ao debate das opiniões dos aprendizes sobre as obras lidas, solicita que produzam um texto literário escrito no qual façam alguma alteração no enredo, dando um final diferente para o livro ou um destino distinto para algum dos personagens. Cabe 
mencionar que o tamanho do texto que o professor deve solicitar precisa estar em concordância com o nível de proficiência dos alunos: enquanto para alunos iniciantes é recomendável que o professor solicite apenas um parágrafo, para alunos avançados é possível uma produção escrita maior. Já na sexta etapa, possivelmente na aula posterior, o professor pede que cada aluno apresente à turma seu texto produzido, não fazendo uma leitura, mas narrando com suas próprias palavras o que alterou na narrativa de alguma das obras lidas e também justifique o porquê de fazer tais mudanças.

Para finalizar esta proposta didática, o professor traz um filme lusófono que foi adaptação de um texto literário, geralmente exibimos um ou dois dos filmes, elencados a seguir: Amor e dedinhos de pé (Dir. Luís Filipe Rocha, 1992) e A trança feiticeira (Dir. Yuanyuan Cai, 1996), baseados nos romances homônimos de Henrique de Senna Fernandes; $O$ testamento do Sr. Napomuceno (Dir. Francisco Manso, 1997), adaptação do romance de Germano Almeida; Terra sonâmbula (Dir. Teresa Prata, 2007) e $O$ último voo do flamingo (Dir. João Ribeiro, 2011), adaptações dos romances de Mia Couto; e $O$ vendedor de passados (Dir. Lula Buarque, 2015), adaptação do romance de José Eduardo Agualusa. A seleção dos filmes também não foi aleatória, pois optamos por trazer filmes tanto das obras trabalhadas em sala de aula, como filmes de textos os quais não solicitamos a leitura. Caso o professor tenha tempo hábil nas aulas, aconselhamos passar dois filmes aos alunos, um que o texto literário foi lido e outro que não foi, com o objetivo de efetuar um debate mais profícuo com os aprendizes, podendo abordar questões das diferenças entre o cinema e o texto literário, as mudanças entre o roteiro do filme e do romance lido, se há semelhanças entre o filme o qual o aprendiz não conhecia, ou não leu o texto literário, e o outro romance lido do mesmo autor.

Segue a lista das sete etapas do trabalho pluricêntrico com os textos literários:

Seleção e leitura das obras literárias;

Informações sobre os autores, os países e o contexto histórico de cada narrativa;

Debate sobre diferentes aspectos culturais encontrados nas obras e as opiniões dos aprendizes sobre o comportamento dos personagens;

Trabalho com as competências lexical e gramatical;

Produção textual escrita a respeito do que o aluno mudaria no enredo;

Apresentação oral dos alunos contando sua versão da história (baseada na produção escrita);

Assistir a um filme e efetuar um debate a respeito, relacionando-o com os textos literários lidos. 
Desta maneira, o que destacamos nas sete etapas acima é que se trata de um roteiro, o qual pode ser seguido passo a passo, alterado, reduzido ou desenvolvido para se efetuar um trabalho didático tanto com um texto literário apenas, quanto com vários, o que é a ideia principal dele. Vale lembrar também que esse roteiro pode ser replicado e adaptado para se abordar diferentes assuntos linguísticos e/ou culturais no ensino de PLNM e relacioná-los com o texto literário, bem como realizar um trabalho com outras linguagens artísticas, como música, dança, teatro e pintura/desenho.

\section{Considerações finais}

No presente trabalho, elaboramos uma proposta didática para trabalhar textos literários lusófonos, com ênfase na África, Macau e Timor-Leste, na aula de PLNM, de acordo com uma perspectiva pluricêntrica. Assim, começamos por definir o português como uma língua pluricêntrica para, em seguida, explicarmos a importância do emprego de textos literários no ensino de PLNM.

Elencamos as obras utilizadas em nossos cursos, bem como apresentamos um roteiro de como são elaboradas as aulas e os materiais didáticos de PLNM para um ensino pluricêntrico por meio de textos literários. Nosso roteiro merece destaque pelo fato de servir como uma base, a qual pode ser replicada ou alterada, tanto para trabalhar outros textos, como também outras linguagens artísticas e até outros temas culturais da língua portuguesa.

Ademais, a proposta pluricêntrica surge ao se utilizar mais de um texto literário de origens diferentes, debater com os aprendizes aspectos linguísticos e culturais específicos que apareceram nesses textos dos países lusófonos e compará-los com as normas linguísticas do português.

Como uma maneira de avaliar o impacto da proposta pluricêntrica, aplicamos questionários e fizemos breves entrevistas ao final do curso, tendo como tema a situação do português em países menos conhecidos ou desconhecidos pelos aprendizes, bem como das "peculiaridades" linguísticas e culturais, quando comparados com as normas brasileira e europeia, que eles possam ter aprendido durante o curso. Os alunos de nível avançado destacaram como positivo para a formação deles o conhecimento a respeito da língua portuguesa na África e na Ásia (Macau e Timor-Leste) e afirmaram também a curiosidade em conhecer mais a respeito em cursos futuros. Contudo, digno de nota é que entre os aprendizes iniciantes os resultados foram divididos, com uma parte que gostou e tem intenção de 
aprender mais, mas a outra parte não deseja continuar seus estudos em língua portuguesa, com o objetivo de ter apenas alguns conhecimentos básicos e introdutórios da língua e consideraram que a ênfase em assuntos culturais e de outros países lusófonos não estavam entre as competências que desejavam alcançar.

Finalmente, esperamos que este artigo possa ter contribuído para a prática dos professores de PLNM, fornecendo subsídios para um trabalho pluricêntrico em sala de aula, já que, apesar da rica discussão teórica do pluricentrismo, da lusofonia e do português como língua pluricêntrica e língua internacional, as publicações e os materiais existentes são reduzidos. Com isso, além da contribuição aos professores e à prática de ensino de PLNM, contamos que nossa pesquisa possa preencher tal hiato e instigar outros profissionais a pesquisarem a respeito desse tema.

\section{REFERÊNCIAS}

ALBUQUERQUE, D. Materiais didáticos pluricêntricos e avaliação em aulas de Português Língua Estrangeira (PLE). Revista Linguagem, v. 38, n. 2, 2021.

BIZARRO, R. Linguística e Literatura: uma relação produtiva na aula de LE. In: OLIVEIRA, F.; DUARTE, I. M. (org.). O Fascínio da Linguagem. Porto: Universidade do Porto, 2008. p. 355-364.

DINIZ, L. R. A.; SCARAMUCCI, M. V. R.; STRADIOTTI, L. M. Uma análise panorâmica de livros didáticos de português do Brasil para falantes de outras línguas. In: DIAS, R.; CRISTOVÃO, V. L. (org.). O livro didático de língua estrangeira: múltiplas perspectivas. Campinas, SP: Mercado de Letras. 2009. p. 265-300.

FONSECA, F. I. Da inseparabilidade entre o ensino da língua e o ensino da literatura. In: REIS, C. et al. (org.). Didáctica da língua e da literatura. Coimbra: Almedina/ ILLP/ Faculdade de Letras da Universidade de Coimbra, 2000. v. 1, p. 37-45.

LIMA, S. I. Desenvolvimento da competência intercultural e literatura lusófona em aulas de PLE: relato de uma experiência em turmas de nível B. Relatório de estágio. 2016. Dissertação (Mestrado em Português Língua Segunda/ Estrangeira) - Faculdade de Letras, Universidade do Porto, Porto, 2016.

TAKAHASHI, N. T. Textos literários no ensino de português-língua estrangeira (PLE) no Brasil. 2008. Dissertação (Mestrado em Letras) - Universidade de São Paulo, São Paulo, 2008.

TAKAHASHI, N. T. Leitura literária em português-língua estrangeira (PLE): representações, compreensão e produção textual. 2015. Tese (Doutorado em Letras) Universidade de São Paulo, São Paulo, 2015. 


\section{Como referenciar este artigo}

ALBUQUERQUE, D. Um olhar pluricêntrico no ensino de português língua não materna: o papel das literaturas africana, macaense e timorense. Rev. EntreLínguas, Araraquara, v. 7, n. esp. 6, e021145, dez. 2021. e-ISSN: 2447-3529. DOI: https://doi.org/10.29051/el.v7iesp.6.15427

Submetido em: $30 / 08 / 2021$

Revisões requeridas em: 11/10/2021

Aprovado em: 22/11/2021

Publicado em: 28/12/2021 